\title{
The PI3K/mTOR dual inhibitor NVP-BEZ235 reduces the growth of ovarian clear cell carcinoma
}

\author{
TETSURO OISHI ${ }^{1}$, HIROAKI ITAMOCHI $^{1}$, AKIKO KUDOH $^{1}$, MICHIKO NONAKA $^{1}$, MISAKI KATO ${ }^{2}$, \\ MAYUMI NISHIMURA ${ }^{2}$, NAO OUMI ${ }^{2}$, SEIYA SATO ${ }^{1}$, JUN NANIWA $^{1}$, SHINYA SATO ${ }^{1}$, \\ MUNEAKI SHIMADA $^{1}$, JUNZO KIGAWA ${ }^{2}$ and TASUKU HARADA ${ }^{1}$ \\ ${ }^{1}$ Department of Obstetrics and Gynecology, Tottori University School of Medicine; \\ ${ }^{2}$ Tottori University Hospital Cancer Center, Yonago, Tottori 683-8504, Japan
}

Received January 31, 2014; Accepted April 8, 2014

DOI: $10.3892 /$ or.2014.3268

\begin{abstract}
Patients with clear cell carcinoma of the ovary (OCCC) have poor survival due to resistance to standard chemotherapy. OCCC has frequent activating mutations of the PIK3CA gene. The present study was conducted to clarify the efficacy of the inhibition of the PI3K-AKT-mTOR pathway in OCCC. We used 8 OCCC cell lines and 5 ovarian serous adenocarcinoma (OSAC) cell lines. The mutation status of the $P I K 3 C A$ and KRAS genes was examined by direct sequencing. The $\mathrm{IC}_{50}$ values of NVP-BEZ235 (BEZ235) and temsirolimus were determined by WST-8 assay. Protein expression levels of PI3K-AKT-mTOR pathway molecules were examined by western blotting. Cell cycle distribution was analyzed by flow cytometry. Annexin V staining was used for detecting apoptosis. We also investigated the effects of BEZ235 on OCCC tumor growth in a nude mouse xenograft model. Four of the 8 OCCC cell lines showed a PIK3CA mutation while none of the 5 OSAC cell lines showed a mutation. The $\mathrm{IC}_{50}$ values of BEZ235 for the OCCC cell lines were lower than these values for the OSAC cell lines. The $\mathrm{IC}_{50}$ value of temsirolimus was higher than BEZ235 in the OCCC cell lines. The PIK3CA mutation was more frequently noted in OCCC than OSAC cells, but the sensitivity of these cell lines to BEZ235 or temsirolimus was not related to the mutation status. pHER3 and pAkt proteins were expressed more frequently in OCCC compared with OSAC. However, protein expression levels were distributed widely, and were not related to the sensitivity. Treatment with BEZ235 suppressed expression of pAkt, although treatment with temsirolimus did not. OCCC cells
\end{abstract}

Correspondence to: Dr Tetsuro Oishi, Department of Obstetrics and Gynecology, Tottori University School of Medicine, 36-1 Nishicho, Yonago, Tottori 683-8504, Japan

E-mail: tetsuro@med.tottori-u.ac.jp

Abbreviations: PI3K, phosphatidylinositol 3-kinase; PDK1, phosphatidylinositol-dependent kinase 1; mTOR, mammalian target of rapamycin; OCCC, ovarian clear cell carcinoma; OSAC, ovarian serous adenocarcinoma

Key words: clear cell carcinoma, $\mathrm{PI} 3 \mathrm{~K}, \mathrm{mTOR}$, ovarian carcinoma exhibited $\mathrm{G}_{1}$ phase arrest after treatment with BEZ235 and apoptosis with a higher concentration of the agent. BEZ235 significantly inhibited tumor growth in mice bearing OVISE and TU-OC-1 cell tumors. The present study indicated that the PI3K-AKT-mTOR pathway is a potential target for OCCC, and that BEZ235 warrants investigation as a therapeutic agent.

\section{Introduction}

Clear cell carcinoma of the ovary (OCCC) is recognized in the World Health Organization classification of ovarian tumors as a distinct histological entity. Its clinical behavior is distinctly different from other epithelial ovarian cancers (1). OCCC accounts for $3.7-12.1 \%$ of epithelial ovarian cancers $(2,3)$. We found that response rates for platinum-based chemotherapy were $11.1 \%$ for OCCC and $72.5 \%$ for serous adenocarcinoma (SAC), suggesting that OCCC resists conventional platinumbased chemotherapy (4). A novel therapeutic strategy is needed to improve the prognosis of patients with OCCC.

$P I K 3 C A$ is located at the $3 \mathrm{q} 26.3$ locus and encodes the catalytic subunit of the phosphatidylinositol 3-kinase (PI3K), $\mathrm{p} 110 \alpha$ (5). In response to an extracellular signal, the activated p110 $\alpha$ phosphorylates PIP2 to generate PIP3. The PIP3 recruits AKT to the plasma membrane, where it is phosphorylated and activated by phosphatidylinositol-dependent kinase 1 (PDK1) and PDK2. Activated AKT can directly activate the mammalian target of rapamycin (mTOR) by phosphorylation at Ser2448. mTOR is a serine/threonine kinase that acts as an effector in the PI3K/Akt pathway. Aberrations of the PI3K pathway are frequently present in many different types of cancer. A number of studies have shown amplification or mutations of the PIK3CA gene in ovarian cancers (6-8). AKT and $\mathrm{mTOR}$ are also hyperactivated in ovarian cancer $(9,10)$. Additionally, a high frequency of activating mutations of PIK3CA has been observed in OCCC (11).

NVP-BEZ235 is an imidazoquinoline derivative that potently and reversibly inhibits class 1 PI3K and mTOR catalytic activity by competing at its ATP-binding site (12). It has been demonstrated to reduce tumor growth in several xenograft models and is currently in clinical trials (12-14). The present study was conducted to clarify the efficacy of NVP-BEZ235 treatment on OCCC. 


\section{Materials and methods}

Cell lines and cell cultures. Eight human OCCC cell lines (OVISE, SMOV-2, KK, TU-OC-1, OVTOKO, KOC-7c, RMG-I and OVMANA) and five OSAC cell lines (KF, KOC-2s, TU-OS-3, TU-OS-4 and SHIN-3) were used. Cells were obtained as follows: OVISE and OVTOKO from Dr Hiroshi Minaguchi (Yokohama City University, Yokohama, Japan); SMOV-2 from Dr Tomohiro Iida (St. Marianna University, Kawasaki, Japan); KK and KF from Dr Yoshihiro Kikuchi (National Defense Medical College, Tokorozawa, Japan); KOC-7c and KOC-2s from Dr Toru Sugiyama (Kurume University, Kurume, Japan); RMG-I from Dr Shiro Nozawa (Keio University, Tokyo, Japan); and SHIN-3 from Dr Yasuhiko Kiyozuka (Nara Medical University, Kashihara, Japan). TU-OC-1, TU-OS-3, and TU-OS-4 cells were established by our department $(15,16)$. All cell lines were maintained in Dulbecco's modified Eagle's medium (DMEM)/F12 (Gibco, Grand Island, NY, USA) with $10 \%$ fetal bovine serum (FBS) in a humidified atmosphere containing $5 \% \mathrm{CO}_{2}$ at $37^{\circ} \mathrm{C}$.

Mutation screening. Screening for mutations was performed as previously described (17). Genomic DNA was purified from all cell lines using a DNeasy Tissue kit (Qiagen, Valencia, CA, USA). PCR primers used to amplify the sequence of interest (exons 9 and 20 of the PIK3CA gene, exons 2 and 3 of the KRAS gene) were the same as reported in the literature $(18,19)$. DNA was amplified in reactions of $30 \mathrm{sec}$ at $94^{\circ} \mathrm{C} ; 30 \mathrm{sec}$ at $55^{\circ} \mathrm{C}$; followed by $90 \mathrm{sec}$ at $72^{\circ} \mathrm{C}$ for 30 cycles. Then, PCR products were subjected to sequencing using BigDye Terminator v3.1 Cycle Sequencing kit and an Applied Biosystems 3130xl Genetic Analyzer (Applied Biosystems Foster City, CA, USA).

Reagents. NVP-BEZ235 and temsirolimus were purchased from LC Laboratories (Woburn, MA, USA). Stock solutions were prepared in dimethyl sulfoxide (DMSO) and stored at $-20^{\circ} \mathrm{C}$ for the in vitro experiments. The drugs were diluted in fresh medium immediately before each experiment. In all the experiments, the final DMSO concentration was $<0.1 \%$.

Dose-response studies. The cytotoxicities of NVP-BEZ235 and temsirolimus were assessed by the WST- 8 assay using Cell Counting Kit-8 (Dojindo Laboratories, Tabaru, Japan) as previously described (17). Cells $\left(2-4 \times 10^{3}\right.$ cells $\left./ 80 \mu \mathrm{l}\right)$ were seeded into each well of a 96 -well tissue culture plate, cultured overnight, and then treated with $20 \mu$ l of NVP-BEZ235 or temsirolimus solution at a final concentration of $0.001,0.01$, $0.1,1$ or $10 \mu \mathrm{M}$ for $72 \mathrm{~h}$. After that, $20 \mu 1$ of Cell Counting Kit- 8 solution was added to each well, and the plates were incubated for another 1-2 $\mathrm{h}$. Absorbance was measured at $450 \mathrm{~nm}$ with a microplate reader (iMark Microplate Absorbance Reader). Cell viability was calculated as the percentage of cells killed by the treatment. All experiments were conducted in triplicate. Median inhibitory concentrations were determined from these calculations.

Western blot analysis. Cells were washed twice with ice-cold PBS. Cell pellets were then lysed in a buffer $[50 \mathrm{mM}$ Tris-HCl (pH 7.5), $150 \mathrm{mM} \mathrm{NaCl}, 10 \%$ glycerol, $1 \%$ NP-40, 2 mM EDTA, $50 \mathrm{mM} \mathrm{NaF}, 2 \mathrm{mM} \mathrm{Na}_{3} \mathrm{VO}_{4}$ and protease inhibitors (Complete
Protease Inhibitor Cocktail Tablets; Roche Diagnostics)] as previously described (17). Protein concentrations were measured against a standardized control using a protein assay kit (Bio-Rad Laboratories). A total of $50 \mathrm{mg}$ protein was separated by electrophoresis on a $5-20 \%$ polyacrylamide gel and transferred to a polyvinylidene difluoride membrane (Millipore). The antibodies were as follows: rabbit anti-erbB3 antibody (C17) (diluted 1:200; Santa Cruz Biotechnology, Santa Cruz, CA, USA), mouse anti- $\beta$-actin (AC-40) antibody (1:1,000; Sigma-Aldrich, St. Louis, MO, USA); and anti-phospho-erbB3 (Tyr1289) (21D3) antibody $(1: 1,000)$, rabbit anti-AKT antibody $(1: 1,000)$, rabbit anti-phospho-AKT (Ser473) antibody (1:500), rabbit anti-mTOR antibody (1:500), rabbit anti-phospho-mTOR (Ser2448) antibody (1:500), rabbit anti-p70S6K antibody (1:500), rabbit anti-phospho-p70S6K (Thr389) antibody (1:500), rabbit anti-4E-BP1 antibody $(1: 1,000)$ and rabbit anti-phospho-4E-BP1 (Thr37/49) antibody $(1: 1,000)$ (all from Cell Signaling Technology (Danvers, MA, USA). Signals were detected with secondary anti-mouse or anti-rabbit immunoglobulin $\mathrm{G}$ antibody coupled with horseradish peroxidase, using an Ez-Capture II chemiluminescent imaging system (ATTO, Tokyo, Japan).

Cell cycle distribution analysis. Cell cycle distribution was analyzed by flow cytometry. Briefly, cells were plated in a 6-well plate, cultured overnight, and then treated with NVP-BEZ235 or left untreated for 48 or $72 \mathrm{~h}$ (final concentration of 10 or $100 \mathrm{nM}$ ). Floating and adherent cells were fixed overnight in ice-cold $70 \%$ ethanol. The cells were then resuspended in PBS containing propidium iodide (PI, $25 \mu \mathrm{g} / \mathrm{ml}$ ) supplemented with $0.1 \%$ RNase A and incubated at $37^{\circ} \mathrm{C}$ for $30 \mathrm{~min}$. DNA content was measured with a FACSCalibur flow cytometer with CellQuest software (Becton-Dickinson, Franklin Lakes, NJ, USA). Cell fit analysis determined the percentage of the cell count in a specific phase of the cell cycle.

Annexin V staining. The Annexin V-FITC Apoptosis Detection kit (BioVision, Mountain View, CA, USA) was used to assess apoptosis as the externalization of phosphatidylserine residues, according to the specifications of the manufacturer. Briefly, cells were suspended in $500 \mathrm{ml}$ of $1 \mathrm{X}$ binding buffer. The cells then were stained with $5 \mathrm{ml}$ Annexin V-FITC (fluorescein isothiocyanate) and $5 \mathrm{ml} \mathrm{PI}(50 \mathrm{mg} / \mathrm{ml})$ for $5 \mathrm{~min}$ in the dark at room temperature. Finally, the cells were analyzed with a flow cytometer (FACSCalibur; Becton-Dickinson).

Ovarian cancer xenograft model. OVISE or TU-OC-1 cells in log-phase growth were trypsinized, washed twice with PBS and centrifuged at $250 \mathrm{x}$ g. For subcutaneous tumor development, $4 \times 10^{6}$ viable cells (in $0.1 \mathrm{ml}$ of PBS) were injected subcutaneously under aseptic conditions into female athymic mice. Seven days after the injection, we confirmed the development of measurable tumors, and then treatment was initiated with NVP-BEZ235 at doses of 25 or $50 \mathrm{mg} / \mathrm{kg} / \mathrm{day}$, and continued for 3 weeks. Mice treated with vehicle (10\% 1-methyl-2-pyrrolidone-90\% polyethylene glycol 300) were used as the control group. All agents were administered by oral gavage. Ten mice were used in each experimental group. The tumor volume was measured with a caliper twice weekly. The body weight of mice was also measured twice weekly. 
Table I. Characteristics of the OCCC and OSAC cell lines.

\begin{tabular}{|c|c|c|c|c|c|c|}
\hline \multirow[b]{2}{*}{ Cell line } & \multirow[b]{2}{*}{ Original tumor } & \multicolumn{2}{|c|}{$K R A S$} & \multirow{2}{*}{$\frac{P I K 3 C A}{\text { Exon } 9}$} & \multirow[b]{2}{*}{ Exon 20} & \multirow[b]{2}{*}{$\mathrm{IC}_{50}$ of BEZ235 (nM) } \\
\hline & & Exon 2 & Exon 3 & & & \\
\hline OVISE & Clear cell carcinoma & wt & wt & wt & wt & 44 \\
\hline SMOV-2 & Clear cell carcinoma & wt & wt & & $3141 \mathrm{~A}>\mathrm{A} / \mathrm{T}$ & 65 \\
\hline KK & Clear cell carcinoma & wt & wt & $1634 \mathrm{~A}>\mathrm{A} / \mathrm{C}$ & wt & 74 \\
\hline TU-OC-1 & Clear cell carcinoma & wt & wt & $1624 \mathrm{G}>\mathrm{G} / \mathrm{A}$ & wt & 131 \\
\hline OVTOKO & Clear cell carcinoma & wt & wt & wt & wt & 534 \\
\hline KOC-7c & Clear cell carcinoma & wt & $\mathrm{wt}$ & wt & wt & 600 \\
\hline OVMANA & Clear cell carcinoma & wt & wt & $1634 \mathrm{~A}>\mathrm{T}$ & wt & 641 \\
\hline RMG-I & Clear cell carcinoma & wt & wt & wt & wt & 777 \\
\hline KF & Serous adenocarcinoma & wt & wt & wt & wt & 779 \\
\hline $\mathrm{KOC}-2 \mathrm{~s}$ & Serous adenocarcinoma & wt & wt & wt & wt & 989 \\
\hline TU-OS-3 & Serous adenocarcinoma & wt & wt & wt & wt & 1,004 \\
\hline TU-OS-4 & Serous adenocarcinoma & wt & wt & wt & wt & 3,951 \\
\hline SHIN-3 & Serous adenocarcinoma & $34 \mathrm{G}>\mathrm{A}$ & wt & wt & wt & 25,400 \\
\hline
\end{tabular}

OCCC, ovarian clear cell carcinoma; OSAC, ovarian serous adenocarcinoma; wt, wild-type.

Statistical analysis. Statistical analyses were performed with Prism version 5 (GraphPad Software Inc., San Diego, CA, USA). Data are presented as means \pm 1 standard error. Means for all data were compared by one-way analysis of variance with post hoc testing or by unpaired t-test. A P-value of $<0.05$ was considered to indicate a statistically significant result.

\section{Results}

Identification of PIK3CA and KRAS mutations in OCCC and OSAC cell lines. We first screened the mutation status of $P I K 3 C A$ (exons 9 and 20) and KRAS (exons 2 and 3) in the 8 OCCC and 5 OSAC cell lines. Four out of the 8 OCCC cell lines showed a PIK3CA mutation while none of the 5 OSAC cell lines showed the mutation (Table I). One of the 5 OSAC cell lines showed a KRAS mutation $(34 \mathrm{G}>\mathrm{A})$ while none of the 8 OCCC cell lines showed this mutation.

Sensitivity to NVP-BEZ235 or temsirolimus. The $\mathrm{IC}_{50}$ values of NVP-BEZ235 in the OCCC cell lines were lower than these values in the OSAC cell lines (Table I). In the OCCC cell lines, the $\mathrm{IC}_{50}$ of temsirolimus was higher than that of BEZ235 (Table II). Although the PIK3CA mutation was more frequently noted in OCCC than OSAC, the sensitivity of these cell lines to NVP-BEZ235 or temsirolimus was not related to the mutation status.

Expression levels of PI3K-Akt-mTOR pathway molecules in the OCCC and OSAC cell lines. Comparison of the OCCC and OSAC cell lines showed that pHER3 and pAkt expression was more frequent in OCCC than OSAC (Fig. 1A). That is, 7 of the 8 OCCC cell lines expressed pHER3 whereas 2 of the 5 OSAC cells lines exhibited expression. Similarly, 6 of the 8 OCCC cell lines expressed pAkt while 2 of the 5 OSAC cell lines did. The protein expression levels were distributed
Table II. $\mathrm{IC}_{50}$ of temsirolimus in the OCCC cell lines.

\begin{tabular}{lcc}
\hline & \multicolumn{2}{c}{$\mathrm{IC}_{50}(\mathrm{nM})$} \\
\cline { 2 - 3 } Cell line & BEZ235 & Temsirolimus \\
\hline OVISE & 44 & 9,122 \\
SMOV-2 & 64 & 8,924 \\
KK & 74 & 5,929 \\
TU-OC-1 & 131 & 7,224 \\
OVTOKO & 534 & 12,776 \\
KOC-7c & 600 & 9,779 \\
OVMANA & 641 & 17,650 \\
RMG-I & 777 & 4,045 \\
\hline
\end{tabular}

widely, and did not relate to the sensitivity to NVP-BEZ235 or temsirolimus.

When OVISE cells were treated with NVP-BEZ235, expression levels of p-p70S6K and p4E-BP1 were suppressed in a dose-dependent manner (Fig. 1B). Treatment with temsirolimus incompletely suppressed p-p70S6K and p4E-BP1 expression in the OVISE cells. Moreover, treatment with NVP-BEZ235 suppressed pAKT expression, while treatment with temsirolimus did not. Similar results were observed in the KK cells (Fig. 1C).

NVP-BEZ235 induces $G_{1}$ phase arrest and apoptosis in OCCC cells. OVISE cells were arrested at the $\mathrm{G}_{1}$ phase, but did not exhibit apoptosis (denoted by an increased proportion of cells in sub- $\mathrm{G}_{1}$ ), after $72 \mathrm{~h}$ of treatment with 10 and 100 nM NVP-BEZ235 (Fig. 2A). We observed similar results of $G_{1}$ arrest in the KK cells (Fig. 2A). Although the same conditions as those in the cell cycle analysis did not induce apoptosis, 
A

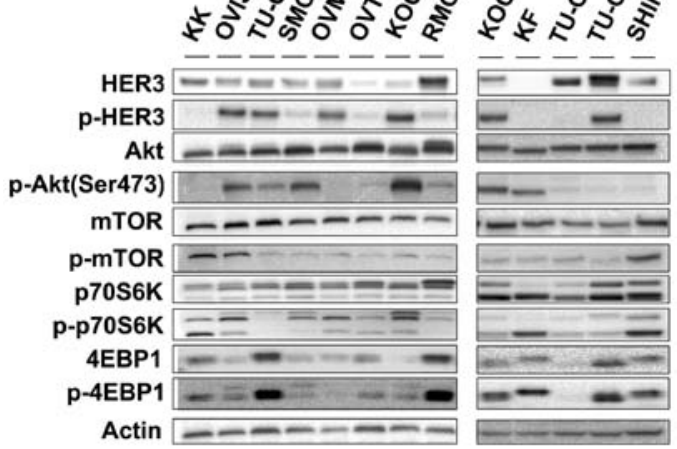

B
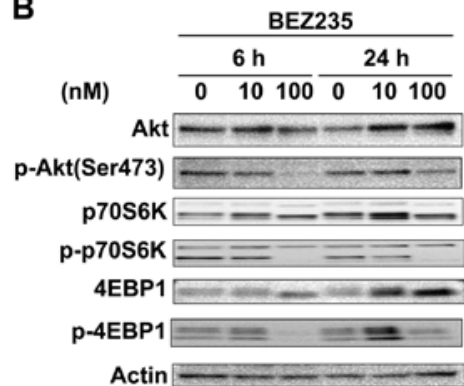

Actin $\square-$

C

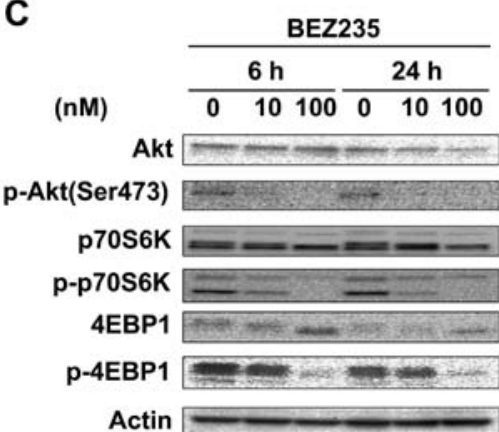

Actin

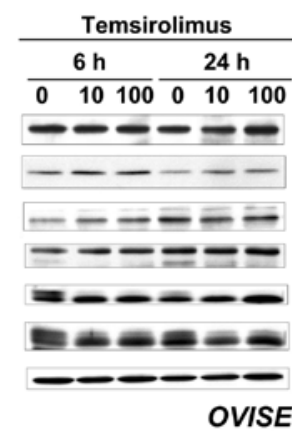

Figure 1. (A) Baseline expression of PI3K-Akt-mTOR pathway molecules in the OCCC and OSAC cell lines. Eight OCCC cell lines (KK, OVISE, TU-OC-1, SMOV-2, OVMANA, OVTOKO, KOC-7c and RMG-I) and 5 OSAC cell lines (KOC-2s, KF, TU-OS-3, TU-OS-4 and SHIN-3) were cultured in DMEM/F12 medium with $10 \%$ fetal bovine serum in a humidified atmosphere containing $5 \% \mathrm{CO}_{2}$ at $37^{\circ} \mathrm{C}$. Western blot analysis was performed to detect the expression levels of HER3, p-HER3, Akt, p-Akt, mTOR, p-mTOR, p70S6K, p-p70S6K, 4E-BP1 and p-4E-BP1. $\beta$-actin was used as a loading control. Each experiment was repeated 3 times independently. (B and C) NVP-BEZ235 suppressed pAkt expression in OCCC cells. Two OCCC cell lines (OVISE and KK) were plated in 6-well plates. The protein samples were collected after treatment with 10 and $100 \mathrm{nM}$ NVP-BEZ235 or temsirolimus for 6 or $24 \mathrm{~h}$. Western blot analysis was performed to detect Akt, p-Akt, p70S6K, p-p70S6K, 4E-BP1 and p-4E-BP1 expression. $\beta$-actin was used as a loading control.

treatment of OVISE cells with 1 or $5 \mu \mathrm{M}$ of NVP-BEZ235 for $96 \mathrm{~h}$ increased the number of Annexin V-positive and PI-negative cells (Fig. 2B). Similar results were observed in the KK cells (Fig. 2B).

NVP-BEZ235 suppresses tumor growth in an OCCC xenograft model. To assess short-term systemic toxicity of the agent, we recorded body weight changes of mice in addition to visual
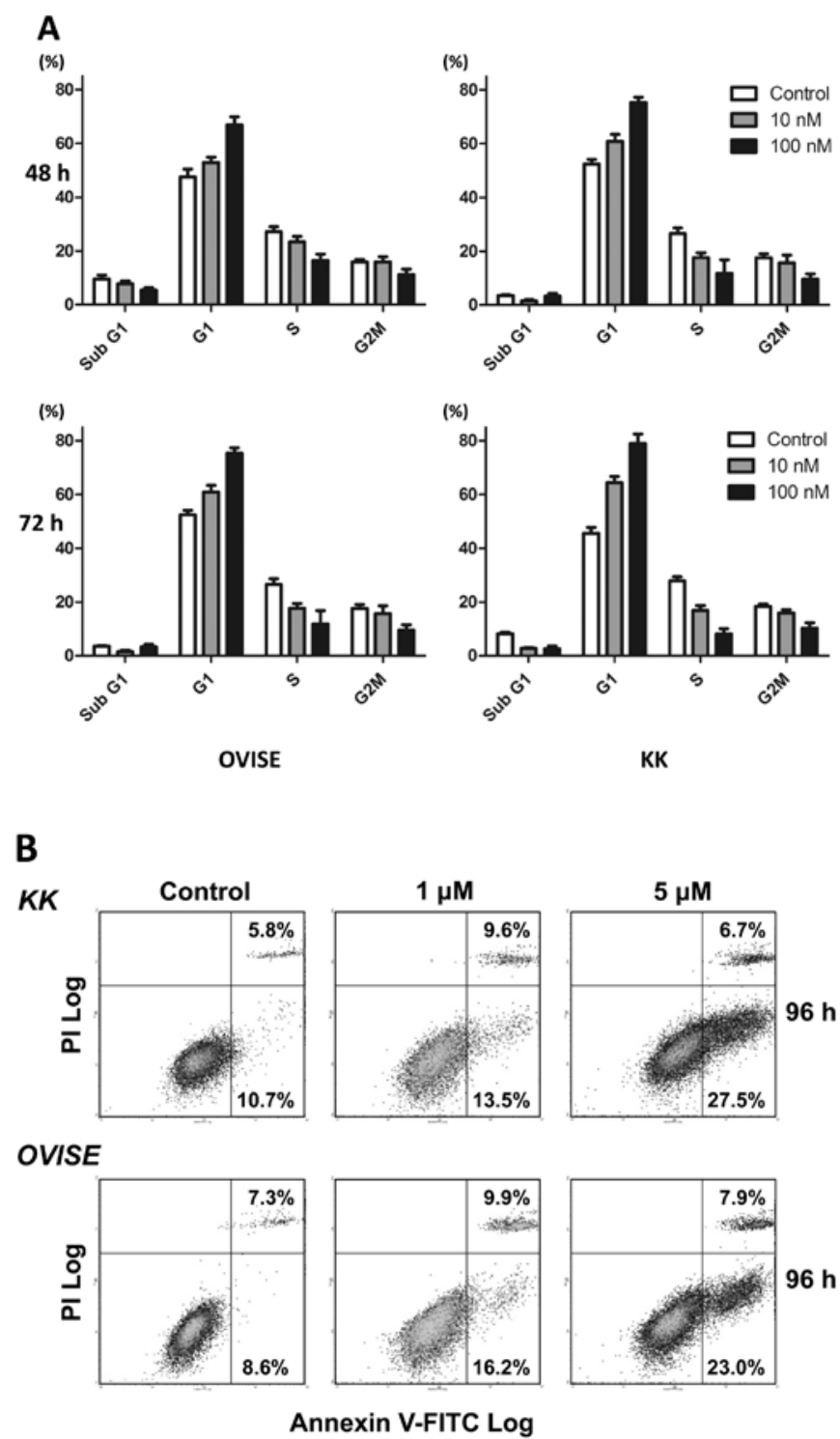

Figure 2. (A) NVP-BEZ235 induced $\mathrm{G}_{1}$ phase arrest in the OCCC cells. OVISE or KK cells were treated with 10 or $100 \mathrm{nM} \mathrm{NVP-BEZ235} \mathrm{for} 48$ or $72 \mathrm{~h}$. FACScan analysis was performed to detect the cell cycle distribution. (B) NVP-BEZ235 induced apoptosis in the OCCC cells. OVISE and KK cells were treated with 1 or $5 \mu \mathrm{M}$ NVP-BEZ235 for $96 \mathrm{~h}$. Apoptosis was determined by the Annexin V-FITC Apoptosis Detection kit. Early apoptotic cells were scored as Annexin V-FITC-positive and propidium iodide (PI)-negative to exclude necrotic cells.

observation. After treatment, no mice had detectable changes in body weight, implying that there was no severe toxicity (Fig. 3A). At doses of 25 or $50 \mathrm{mg} / \mathrm{kg} / \mathrm{day}$, NVP-BEZ235 significantly inhibited subcutaneous tumor growth in mice bearing OVISE cells $(\mathrm{P}<0.05$ for $25 \mathrm{mg} / \mathrm{kg} / \mathrm{day}, \mathrm{P}<0.01$ for $50 \mathrm{mg} / \mathrm{kg} / \mathrm{day}$ ) (Fig. 3B). TU-OC-1 tumor volume in the $50 \mathrm{mg} / \mathrm{kg} /$ day group was significantly lower than that of the vehicle control although that in the $25 \mathrm{mg} / \mathrm{kg} / \mathrm{day}$ group was not $(\mathrm{P}<0.01$ for $50 \mathrm{mg} / \mathrm{kg} /$ day) (Fig. 3C).

\section{Discussion}

Many authors have reported poorer prognoses for patients with advanced stage OCCC $(4,20,21)$. Low survival rates in OCCC 

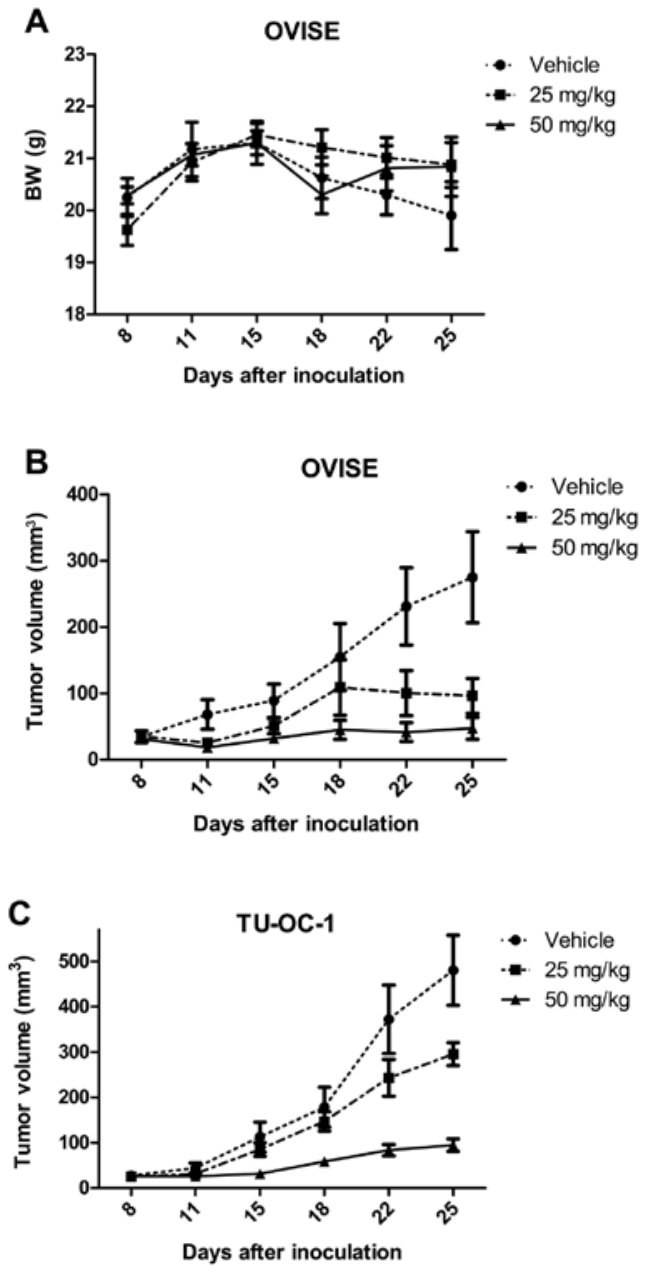

Figure 3. NVP-BEZ235 inhibits tumorigenicity in an OCCC xenograft model without producing toxic effects. Female athymic nude mice were injected subcutaneously with $4 \times 10^{6}$ OVISE or TU-OC-1 cells. The experimental groups were treated with vehicle control (10\% 1-methyl-2-pyrrolidone-90\% polyethylene glycol 300), or 25 or $50 \mathrm{mg} / \mathrm{kg} /$ day NVP-BEZ235 for 3 weeks beginning 7 days after cell injection. (A) Mean body weight in each treatment group. (B and C) The tumor volume in OVISE or TU-OC-1 xenografts was measured with a caliper twice weekly. Error bars represent the standard error.

may, in part, reflect its lack of sensitivity to platinum-based chemotherapy. There are no antineoplastic agents definitely active and effective to treat OCCC. Therefore, novel therapeutic strategies, including targeted therapy, are needed to improve the prognosis of patients with OCCC.

It is known that mutations of $P I K 3 C A$ are common molecular genetic alterations identified in OCCC (11). Expression of phospho-mTOR was found to be more prominent in OCCC than in OSAC (22). mTOR exists in two distinct complexes, mTOR complex 1 (mTORC1) and mTORC2. The downstream targets of mTORC1 are p70 ribosomal S6 kinase 1 (p70S6K) and eukaryotic translation initiation factor 4E-binding protein 1 (4E-BP1), both of which are crucial to the regulation of protein synthesis.

In practice, inhibitors of mTORC1, such as temsirolimus and everolimus, have been used for renal cell carcinoma. A phase II study (GOG268) combining temsirolimus with carboplatin and paclitaxel following temsirolimus consolidation as first-line therapy is underway in patients with OCCC (23). However, the efficacy of mTORC1 blockade may be attenuated due to the loss of an mTORC1-dependent negative feedback loop on PI3K signaling and the mTORC2-mediated activation of Akt (24). p70S6K inhibits insulin receptor substrate 1 (IRS-1) by phosphorylating it, by inducing it to degrade and by altering its localization $(25,26)$. The inhibition of IRS by p70S6K attenuates PI3K-AKT activation. Rapamycin (and its analogs temsirolimus and everolimus) stops this negative feedback loop from the p70S6K to the PI3K signaling pathway, resulting in activation of proliferative and prosurvival effectors such as AKT.

NVP-BEZ235 is a dual pan-class I PI3K and an mTOR kinase inhibitor that has the possible advantage of inhibiting PI3K, mTORC1 and mTORC2. Therefore, it should turn off this pathway completely and overcome feedback inhibition that is normally observed with mTORC1 inhibitors (e.g. rapamycin analogs). It is known that NVP-BEZ235 displays significant antitumor activities in glioblastoma, lung, breast, renal cell and uterine endometrial carcinomas $(12,14,13,27)$.

In the present study, $\mathrm{IC}_{50}$ of temsirolimus was markedly higher than NVP-BEZ235 in all OCCC cell lines. In contrast, NVP-BEZ235 effectively suppressed proliferation of OCCC cells. Additionally, treatment with temsirolimus increased expression of pAKT while p-p70S6K and p4E-BP1 were suppressed. Treatment with NVP-BEZ235 suppressed pAkt, p-p70S6K and p4E-BP1. Accordingly, NVP-BEZ235 may be the more effective agent.

We found that NVP-BEZ235 suppressed tumor growth in an OCCC xenograft model. A few authors have reported on the antitumor activity of this compound in ovarian carcinoma. Montero et al (28) showed that NVP-BEZ235 effectively suppressed proliferation of 4 ovarian carcinoma cell lines which were not derived from OCCC. Santiskulvong et al (29), investigated the in vivo effects of NVP-BEZ235 on an immunocompetent transgenic murine ovarian endometrioid adenocarcinoma model. They also examined in vitro activity of the compound in 17 human ovarian carcinoma cell lines including 2 OCCC cell lines (ES-2 and OV207). Unfortunately, these studies did not focus on OCCC. Recently, Rahman et al (30) investigated the frequency of PIK3CA mutations in patients with OCCC and the relationship between the mutations and clinicopathological or biological variables. They also examined the in vitro sensitivity of 9 OCCC cell lines to LY294002, temsirolimus and NVP-BEZ235. No relationship was observed between the mutation status and sensitivity to these inhibitors. We also examined the mutation status of $P I K 3 C A$ and $K R A S$ genes and baseline protein expression levels of the PI3K/Akt/mTOR pathway molecules. Although the PIK3CA mutation was more common in OCCC than in OSAC in our series, there were no relationships between the mutation status or protein expression levels and sensitivity to NVP-BEZ235. These findings supported those of a previous report (30).

Our results revealed that NVP-BEZ235 effectively suppressed not only p-p70S6K and p4E-BP1, but also pAKT expression in OCCC cell lines and suppressed tumor growth in an OCCC xenograft model. This is the first report to demonstrate the efficacy of NVP-BEZ235 in OCCC.

We conclude that the PI3K-AKT-mTOR pathway is a potential therapeutic target for OCCC and that NVP-BEZ235 warrants investigation as a therapeutic agent. 


\section{Acknowledgements}

We thank Dr Kazuyuki Kitatani of the Medical Megabank Organization at Tohoku University for providing technical advice and Dr Yuji Nakayama and Ms. Hiromi Miyauchi of the Division of Functional Genomics, Research Center for Bioscience and Technology at Tottori University for assisting with the cell cycle analysis. The present study was supported by the Project for Development of Innovative Research on Cancer Therapeutics, from the Ministry of Education, Culture, Sports, Science and Technology of Japan and Grant-in-Aid for Scientific Research from the Ministry of Education, Culture, Sports, Science, and Technology of Japan (25462594 to T.O.).

\section{References}

1. Scully RE: World Health Organization classification and nomenclature of ovarian cancer. J Natl Cancer Inst Monogr 42: 5-7, 1975.

2. McGuire V, Jesser CA and Whittemore AS: Survival among U.S. women with invasive epithelial ovarian cancer. Gynecol Oncol 84: 399-403, 2002.

3. Kennedy AW, Biscotti CV, Hart WR and Webster KD: Ovarian clear cell adenocarcinoma. Gynecol Oncol 32: 342-349, 1989.

4. Sugiyama T, Kamura T, Kigawa J, et al: Clinical characteristics of clear cell carcinoma of the ovary: a distinct histologic type with poor prognosis and resistance to platinum-based chemotherapy. Cancer 88: 2584-2589, 2000.

5. Courtney KD, Corcoran RB and Engelman JA: The PI3K pathway as drug target in human cancer. J Clin Oncol 28: 1075-1083, 2010

6. Nakayama K, Nakayama N, Kurman RJ, et al: Sequence mutations and amplification of PIK3CA and AKT2 genes in purified ovarian serous neoplasms. Cancer Biol Ther 5: 779-785, 2006.

7. Zhang L, Huang J, Yang N, et al: Integrative genomic analysis of phosphatidylinositol 3'-kinase family identifies $P I K 3 R 3$ as a potential therapeutic target in epithelial ovarian cancer. Clin Cancer Res 13: 5314-5321, 2007.

8. Campbell IG, Russell SE, Choong DYH, et al: Mutation of the PIK3CA gene in ovarian and breast cancer. Clin Cancer Res 64: $7678-7681,2004$

9. Altomare DA, Wang HQ, Skele KL, et al: AKT and mTOR phosphorylation is frequently detected in ovarian cancer and can be targeted to disrupt ovarian tumor cell growth. Oncogene 23: 5853-5857, 2004.

10. Mabuchi S, Kawase C, Altomare DA, et al: $m T O R$ is a promising therapeutic target both in cisplatin-sensitive and cisplatinresistant clear cell carcinoma of the ovary. Clin Cancer Res 15: 5404-5413, 2009.

11. Kuo KT, Mao TL, Jones S, et al: Frequent activating mutations of PIK3CA in ovarian clear cell carcinoma. Am J Pathol 174: 1597-1601, 2009.

12. Maira SM, Stauffer F, Brueggen J, et al: Identification and characterization of NVP-BEZ235, a new orally available dual phosphatidylinositol 3-kinase/mammalian target of rapamycin inhibitor with potent in vivo antitumor activity. Mol Cancer Ther 7: 1851-1863, 2008.
13. Brachmann S, Hofmann I, Schnell C, et al: Specific apoptosis induction by the dual PI3K/mTOR inhibitor NVP-BEZ235 in HER 2 amplified and PIK3CA mutant breast cancer cells. Proc Natl Acad Sci 106: 22299-22304, 2009.

14. Cho DC, Cohen MB, Panka DJ, et al: The efficacy of the novel dual PI3-kinase/mTOR inhibitor NVP-BEZ235 compared with rapamycin in renal cell carcinoma. Clin Cancer Res 16: 3628-3638, 2010

15. Itamochi $\mathrm{H}$, Kato $\mathrm{M}$, Nishimura $\mathrm{M}$, et al: Establishment and characterization of a novel ovarian serous adenocarcinoma cell line, TU-OS-4, that overexpresses EGFR and HER2. Hum Cell 25: 111-115, 2012.

16. Itamochi H, Kato M, Nishimura M, et al: Establishment and characterization of a novel ovarian clear cell carcinoma cell line, TU-OC-1, with a mutation in the PIK3CA gene. Hum Cell 26: 121-127, 2013.

17. Itamochi H, Oishi $\mathrm{T}$, Shimada M, et al: Inhibiting the mTOR pathway synergistically enhances cytotoxicity in ovarian cancer cells induced by etoposide through upregulation of c-Jun. Clin Cancer Res 17: 4742-4750, 2011.

18. McIntyre AJ, Summersgill BM, Spendlove HE, et al: Activating mutations and/or expression levels of tyrosine kinase receptors $G R B 7, R A S$, and $B R A F$ in testicular germ cell tumors. Neoplasia 7: 1047-1052, 2005.

19. Li VSW, Wong CW, Chan TL, et al: Mutations of PIK3CA in gastric adenocarcinoma. BMC Cancer 5: 29, 2005.

20. Rauh-Hein AJ, Winograd D, Growdon WB, et al: Prognostic determinants in patients with uterine and ovarian clear carcinoma. Gynecol Oncol 125: 376-380, 2012.

21. Pectasides D, Fountzilas G, Aravantinos G, et al: Advanced stage clear-cell epithelial ovarian cancer: the Hellenic Cooperative Oncology Group experience. Gynecol Oncol 102: 285-291, 2006.

22. Miyazawa M, Yasuda M, Fujita M, et al: Therapeutic strategy targeting the mTOR-HIF-1 $\alpha$-VEGF pathway in ovarian clear cell adenocarcinoma. Pathol Int 59: 19-27, 2009.

23. Itamochi $\mathrm{H}$ and Kigawa J: Clinical trials and future potential of targeted therapy for ovarian cancer. Int J Clin Oncol 17: 430-440, 2012.

24. Efeyan A and Sabatini DM: mTOR and cancer: many loops in one pathway. Curr Opin Cell Biol 22: 169-176, 2010.

25. Harrington LS, Findlay GM, Gray A, et al: The TSC1-2 tumor suppressor controls insulin-PI3K signaling via regulation of IRS proteins. J Cell Biol 166: 213-223, 2004.

26. Hartley D and Cooper GM: Role of mTOR in the degradation of IRS-1: regulation of PP2A activity. J Cell Biochem 85: 304-314, 2002.

27. Shoji K, Oda K, Kashiyama T, et al: Genotype-dependent efficacy of a dual PI3K/mTOR inhibitor, NVP-BEZ235, and an mTOR inhibitor, RAD001, in endometrial carcinomas. PLoS One 7: e37431, 2012.

28. Montero JC, Chen X, Ocaria A, et al: Predominance of mTORC1 over mTORC 2 in the regulation of proliferation of ovarian cancer cells: therapeutic implications. Mol Cancer Ther 11: 1342-1352, 2012.

29. Santiskulvong C, Konecny GE, Fekete M, et al: Dual targeting of phosphoinositide 3-kinase and mammalian target of rapamycin using NVP-BEZ235 as a novel therapeutic approach in human ovarian carcinoma. Clin Cancer Res 17: 2373-2384, 2011.

30. Rahman M, Nakayama K, Rahman MT, et al: Clinicopathologic and biological analysis of PIK3CA mutation in ovarian clear cell carcinoma. Hum Pathol 43: 2197-2206, 2012. 